\title{
The Form of the Digital Medium as a Driver of a Participatory Approach in Teaching and Learning
}

\author{
Alessio Ceccherelli*
}

\author{
University of Rome Tor Vergata, Italy
}

\begin{abstract}
Media characterize teaching methods both for the historical (when they were conceived or widespread), the communicative (the relationship between the subjects of the teaching process), and the cultural aspect (the concept of knowledge in the relationship between subjects and objects of teaching/learning). The lesson derives from the "book" form, becoming unidirectional with the emergence of electrical technologies; Skinner's programmed instruction also appears in the electric age, and so on. Today, network technologies are structurally related to self-discovery learning paths (such as in gamification strategies) and collaborative methodologies (cooperative learning, PBL, CBL, project-based learning); moreover, the continuous handling of digital technologies imposes a different conception of knowledge. It is precisely these media characteristics that suggest a didactic approach based on interactivity and horizontal participation, new concepts that can be exploited and put into practice by old words: dialogue and negotiation. If the former refers to the never outdated Socratic system and to the need for the teacher to put himself in a situation of listening, negotiation becomes a way of interaction that can be established at every level of the teaching/learning process, from the choice of some contents to the setting of evaluation criteria. The paper shows an example of this approach in a blended university course held for four years, where some of these strategies occurred: group works, peer evaluation, co-responsibility of evaluation criteria, and a partially free choice about the contents to be studied and learnt.
\end{abstract}

Keywords: media education; negotiation; maieutics; teaching methods

\section{Introduction}

Teachers know that one of the most considerable difficulties of this work is the motivation of students and their interest in the topics they intend to address. This situation also applies to the university, a context of noncompulsory education in which this type of problem should not exist, for it is assumed that one chooses a university course precisely because of interest. Nonetheless, one of the main reasons that led Howard Barrows (1996) to conceive, at the end of the 1960s, a methodological approach based on problems was precisely the consideration that traditional medical education was not able to motivate students sufficiently. Students perceived the didactic material provided during the first years of study as of little relevance for the practice of medicine and clinical medicine.

The main question of teaching concerns the method more than the content, the process more than the product, and it is crucial to understand which methodological approaches are more appropriate today. As a university lecturer, I have been thinking over the years about what teaching form could allow students to live productive and engaging learning experiences. The method commonly used at university is based on a transmissive relational system that seems less and less suitable for the communicative styles of today's students. They have cultural habits and characteristics that depend to a large extent on how they communicate and how they interact with objects of knowledge. Usually, they relate and interact through the digital medium, which encourages direct involvement. 
The idea that I intend to discuss in this article is that the current cultural period seems to require a horizontal and participatory didactic approach, not only as a result of the pedagogical reflection of the last decades (the lecture has been questioned for more than a century, leading to participatory didactic strategies) but also in consideration of the characteristics of the medium that is prevalent nowadays.

\section{Materials and Methods}

The course described below has been held in the last four years at the University of Rome Tor Vergata, for a bachelor's degree in Education and Training Sciences. It should be considered as an example of the epistemological triangle of praxis-theory-praxis on which the teaching profession is based: theoretical reflection develops on feedback gathered in classroom practice, which in turn is influenced by the results of reflection, in a virtuous circle that aims at continuous improvement.

The methodologies used to analyse the effects of the didactic approach are both quantitative (two surveys) and qualitative (the series of free considerations that the students have provided at my request).

\section{A personal case study for self-reflection}

Although the classic method of the lesson is still useful in some educational contexts, overcoming the lectureexamination scheme was the conditio sine qua non from which to start; but what helped me to design and redesign the course I held for four years at the University of Rome Tor Vergata was the reasoning on the relationship between the effectiveness of teaching methods and the medium of reference. In the second half of the twentieth century, several studies reflected on the role of media in the evolution of culture and society (McLuhan, 1964, Ong, 1982; De Kherkhove, 1991, Bolter and Grusin, 1999, Mithen, 1996; Debray, 2000, Mithen, 2001). Every medium has its own personal and social consequences:

"The medium is the message. This is merely to say that the personal and social consequences of any medium - that is, of any extension of ourselves - result from the new scale that is introduced into our affairs by each extension of ourselves, or by any new technology." (McLuhan, 1964, p. 7)

The evolution of the media influences the relational and communicative system of human beings, and didactics is first and foremost communication. This is the starting point to consider the digital medium not so much as a set of tools to be used, but for its structure and functioning: as form more than content.

Two are the most relevant characteristics from an educational point of view. The first deals with the possibility of continuous interaction: a digital object can be easily readapted, assembled, customized, re-functionalized. In some of its forms, such as video games, this interaction becomes structural, moving to interactivity. Furthermore, the video games' sophisticated feedback system provides the player with constant 'evaluative' information on his/her behaviour during the game: a player immediately knows if his/her actions and choices head to success or failure (Gee, 2007, Young \& Slota, 2017). The second feature regards the concept of the net. This is not fully part of the digital world because we have examples also in the past (i.e., the roads of the Roman Empire, the railway system in the nineteenth century, the electricity), but it is only with ICTs that the net takes on a global, widespread and permanent dimension in space and time.

How can interaction and networking be translated into didactic strategies? Two words come to mind in this case: dialogue and negotiation. The former, of course, has a broad educational significance (Freire, 1970, Skidmore \& Murakami, 2016); as Socrates taught, a teacher should put himself in a listening position, trying to elicit knowledge from the student, as the etymology of education suggests (ex-ducere, 'lead out'): knowledge is not transferred but brought out, somehow it is rediscovered together. The latter is about confrontation (intended as a positive exchange of opinions) and participation. The academic education system tends to predetermine almost 
all aspects: curricula, times, spaces are decided in advance by teachers, as well as methods, evaluation tools, and evaluation criteria. Perhaps something among these aspects can be built together with those who play the most critical role in the educational process, namely the students. It does not mean delegating, but discussing, sharing, increasing in them the awareness of how important it is to learn and self-educate, from the very beginning, before dealing with the content and beyond the assessment (Soderstorm \& Bjork, 2015). The role of the teacher is to enable effective negotiation, preparing the educational environment, declaring the rules and roles, and managing the whole process.

Inspired by these concepts and with a gamified horizon in mind (Kapp, 2012), the course was broken down into main content (the primary mission) and further deepening content (the secondary missions), assigning different scores to tests (MCQs, open-ended answers, essays, oral tests) and giving students a certain degree of decision on the self-construction of their learning path. Apart from some mandatory activities on the basic notions of the course, there were no standard paths: everyone could decide what to study and what not to study, what to deepen and what not to deepen.

The course provided an online discussion forum, open for two months, in which both attending and nonattending students were called to discuss topics launched periodically. The role of the forum is twofold. First, it is the place of confrontation par excellence, a place where students can express themselves and their opinions. Moreover, through the writing of the posts, I had the opportunity to have additional data on individual participants, such as argumentative ability, writing skills, spelling accuracy, originality of thought: all information that allowed to solve doubts about some final evaluations.

Students were expressly encouraged to take the responsibility of the quantity and quality of their learning: they were free to choose not to upload the paper, or not to participate in the forum, or to do only some of the quizzes, etc. Of course, the more activities they did, the higher the chance of getting a good grade, and this grade was the result of different evaluation dimensions (objective, subjective and - for those attending - intersubjective), of different types of tests (structured, semi-structured, open), of different manners (individual and collective, written and oral). The diversification of examinations is intended to give students a more complex and multifaceted meaning of their grade (Stiggins et al., 2007, Fuentealba, 2011). (Figure 1)

\begin{tabular}{|c|c|c|}
\hline \multicolumn{2}{|c|}{ Attending students } \\
\hline Activities & Points & Dim \\
\hline Thematic paths & 2,5 & O \\
\hline Tests & 10 & O \\
\hline Quick test (MCQ) & 2 & O \\
\hline Reasoned test & 2 & S \\
\hline Team work - Written report & 5 & S \\
\hline Team work - Oral presentation & 10 & I - S \\
\hline Forum & 2,5 & S \\
\hline Total & $\mathbf{3 4}$ & \\
\hline
\end{tabular}

\begin{tabular}{|c|c|c|}
\hline \multicolumn{2}{|c|}{ Non-Attending students } \\
\hline Activities & Points & Dim \\
\hline Thematic paths & 2,5 & $\mathrm{O}$ \\
\hline Tests & 10 & $\mathrm{O}$ \\
\hline Quick test (MCQ) & 2 & $\mathrm{O}$ \\
\hline Reasoned test & 2 & $\mathrm{~S}$ \\
\hline Individual work - Essay & 5 & $\mathrm{~S}$ \\
\hline Individual study - Oral & 10 & $\mathrm{~S}$ \\
\hline Forum & 2,5 & $\mathrm{~S}$ \\
\hline Total & $\mathbf{3 4}$ & \\
\hline
\end{tabular}

Figure 1. The different scores assigned to the different activities, with an indication of the evaluation dimension (Objective, Subjective, Inter-subjective). The final sum of the scores goes beyond 30 as a maximum of votes, so as not to penalize too much the possible errors

Some tests were in common between attending and non-attending students and had to be taken individually. Students that decided not to attend the course preferred the self-learning logic. With them, the negotiation was 
minimal, only for the choice of the topic to deepen in the essay: they proposed something, and we discussed whether it was appropriate or not.

On the contrary, with the students attending, negotiation and dialogue took place during all phases of the process. They were divided into groups, and in a specific negotiation session each participant indicated two key topics of the course not developed in the lessons; all together we then proceeded to identify the topics to be investigated, assigning one for each group. The first work required was the upload of a written report, evaluated only by the teacher. A second work was the presentation of the research results in class. They were free to choose the style of the presentation, by using slides, playing a video, reporting on interviews made, putting posters on the walls of the room, producing a theatrical performance, and so on. The work was evaluated by all the other groups and me, in an approach of mutual evaluation: my grade averaged that of the other groups, so the final grade was the expression of about 70-90 people (the usual number of attending students). The most important thing about this activity is that the grade assigned referred to an Assessment Rubric built together by the students and me, during another specific negotiation session held before the presentation. In this rubric, dimensions, criteria, and indicators were identified together, so that each group immediately knew what would be evaluated, before proceeding with the research work.

\section{Data collection}

To obtain the students' perspective on this four-year learning practice, and understand if the underlying hypothesis on the relation between teaching methods and media is valid and practicable, some feedback was collected with both qualitative and quantitative methods. At the end of the course, students could self-assess, freely writing their opinion on the learning system and the effectiveness of their study.

Besides, two surveys were launched. The first is predefined in the virtual learning environment used in the course (Moodle). It is the Attitudes Towards Thinking and Learning Survey - ATTLS (Galotti et al. (1999), designed for measuring the extent to which a person can be considered a 'connected knower' or a 'separate knower'. The former tend to find learning more enjoyable and are often more cooperative, congenial and more willing to build knowledge on the ideas of others, while the latter prefer to take a more critical and argumentative attitude. ATTLS was addressed to students only in the last three academic years (2016/2017, 2017/2018, 2018/2019).

The second survey was constructed, taking into consideration the main characteristics of the course, trying to investigate their impact on understanding and interest in the topics covered. The 11 questions were focused on the possibility to partially choose the learning path, the diversification of study materials (books, articles, videos, slides), the role of quantity and quality of evaluation tests, the importance of the forum. Attending students were also asked to respond to further six questions on the role of collaboration and negotiation activities for motivation and learning: the collaborative choice of topic, the setting of evaluation criteria, the use of a shared evaluation table. This survey was available to students in all the academic years, since 2015/2016. The only condition to be able to respond was to have registered the final grade.

\section{Results}

The students involved in these four years have been about 500, of which 290 attended.

\section{Self-assessment}

About the self-assessment, the students who provided an answer were 162. The main element of interest concerns the opportunity to communicate with the teacher and the other students on the forum and (for attending students) during the negotiation sessions. The discussion space generally enriched learning, enhancing 
understanding of specific topics and interest in the study. For example, Giulia appreciated the "possibility to build something truly ours, to plan, even if minimally, a part of a teaching-learning path and to self-confront with a working group rediscovering those dynamics of collective study that often may be lost in the routine of an individual path". The discussion tool allowed Adele "to learn also from the other participants and to reevaluate [her] ideas, critically comparing them with those of the other classmates". According to Federica: "learning was facilitated, and [she] think [to] have learned, in addition to the notions about the subject, also how to approach the subject itself, how to use the theoretical notions in real life and how much the dialogue between pairs and with the professor is fundamental".

Compared to the traditional one, the particularity of the educational system also caused some initial orientation troubles. However, continuous practice in the learning environment almost always solved these difficulties, highlighting the positive aspects mentioned. Elena testimonies this process of adaptation: "At the beginning, I did not have much confidence in this 'new' type of distance teaching, but in the end, I had to rethink myself thanks to a teacher always present to clarify our doubts and always in relation with us guys". Gaia, on the other hand, points out a media education factor: "Initially I had difficulty orienting myself in the platform, but the more I continued, the more natural it became for me to move in a course that went far beyond books. Moreover, since learning also means acquiring new models of behaviour, this criticality becomes a positive element”.

\section{First survey}

The appreciation for discussion with other students and teamwork also emerges from the Attitudes Towards Thinking and Learning Survey. The following graph summarizes the 115 responses gathered in the last three years (Figure 2).

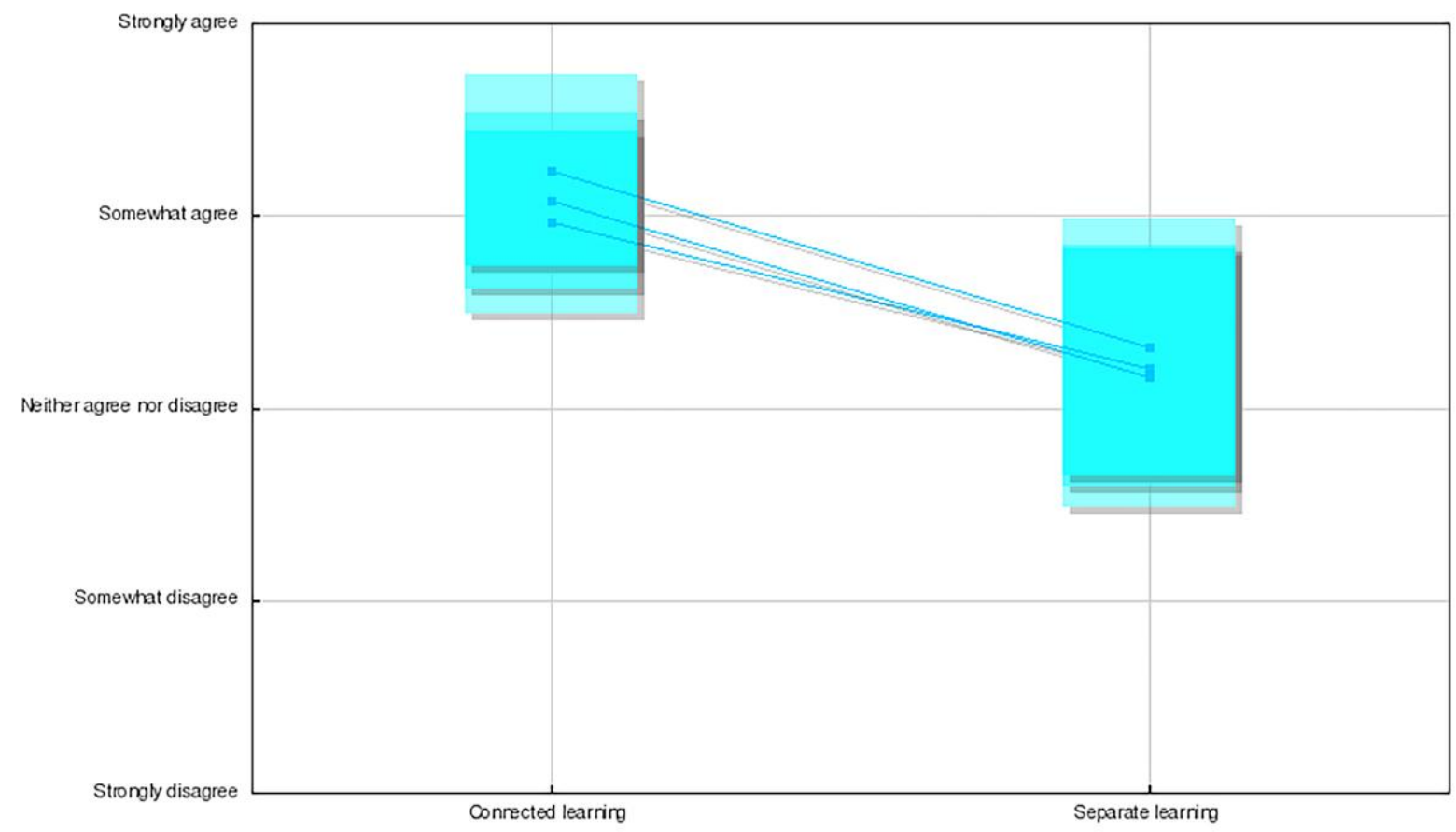

Figure 2. ATTLS overview results in the three years

Although separate learning has obtained an average consensus, there is always a general prevalence of connected learning, and the difference between the two is quite relevant. The positive aspects of the 'separate knower' (objectivity, use of logic, importance of the quality of content, importance of having evaluation criteria) are generally less relevant than the relational elements that emerge in the profile of the 'connected knower' 
(listening to different opinions, knowing the experiences of other students, thinking with people and not against them). The importance of a constructive dialogue emerges rather significantly.

\section{Second survey}

The results of the second survey, more specific to the particularities of the course, also confirm the overall outcomes. The 90 responses show a high prevalence of positive results as regards the innovative elements in the design of the course and the role given to participation (only the more significant graphs are here reported).

The possibility to partially choose the learning path can be considered as the first element of negotiation with the formal structure of a course. It obtained an outstanding appreciation (in total $95 \%$ positive results, summing Agree and Strong agree), and the control on the risk of confusion gives substantial confirmation (in total, only $15 \%$ of total positive results). (Figure 3 )

\section{Q1. The possibility of being able to partly choose what to study and which evaluation tests to carry out has increased my interest in the course.}

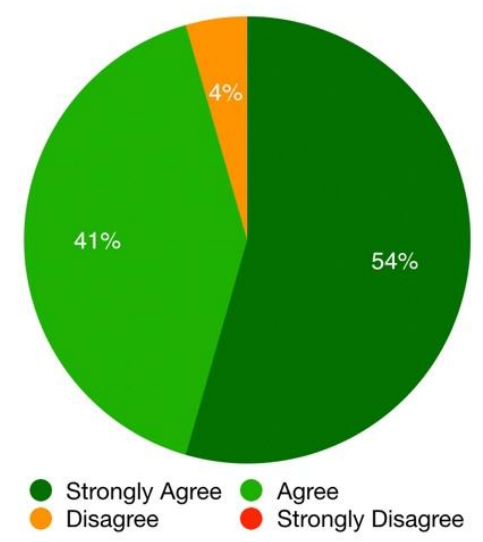

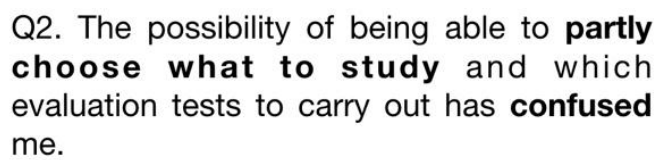

me.

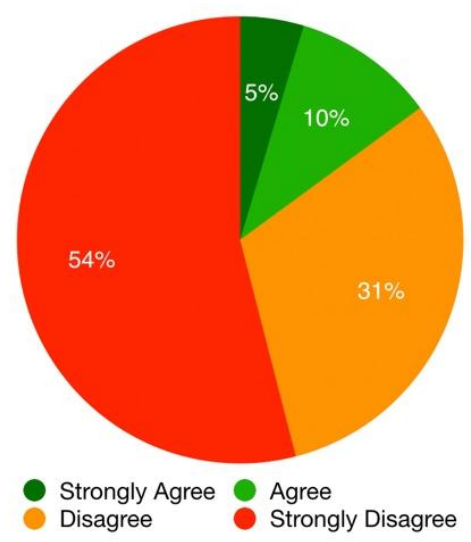

Figure 3. Answers on the possibility to build part of the learning path

The diversification of study materials was also very much appreciated. This aspect is considered both as an added value on the learning experience (in total, $95 \%$ of positive results) and as an element of facilitation (in total, $88 \%$ of positive results).

More composite the results on how the quantity and quality of the evaluation tests impacted the objectivity and value of the grade. Their role in the objectivity of the final grade is considered substantial (in total, $82 \%$ of positive answers for the multiplicity, $78 \%$ for the diversification), but these same characteristics did not contribute to obtaining a higher score than that of the traditional system (30\% and $37 \%$ of negative results). The new system does not affect or facilitate high scores, but generally requires a reasonable effort: it is not enough to be able to choose the course of study and participate in discussions freely. (Figure 4). 
Q7. The multiplicity (therefore the quantity) of evaluation tests allowed me to take a higher grade than a traditional evaluation system.

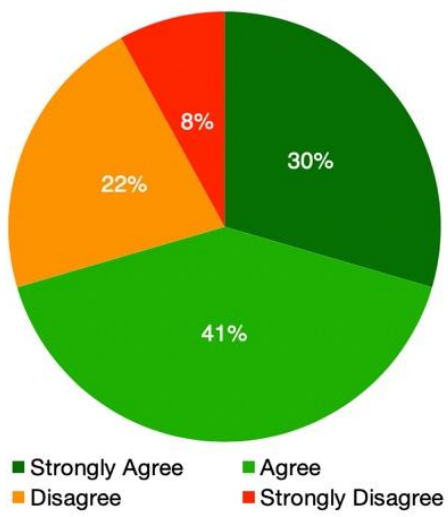

Q8. The diversification (therefore the quality) of evaluation tests allowed me to take a higher grade than a traditional evaluation system.

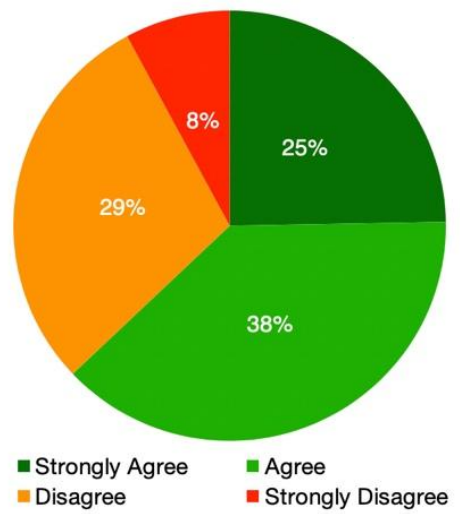

Figure 4. Answers on quantity and quality of evaluation activities (about the attainment of the final grade)

Issues relating to dialogue and negotiation are from question 10 onwards. The first two concerned the forum and were therefore answered by all the students, both attending and non-attending. The $80 \%$ of positive responses reflect the self-assessment outcomes, in terms of interest and understanding of the course content.

The other moments of negotiation concerned the group activity of the students attending (67 out of 90). Apart from the confirmation of the importance of collaborative activities in motivating and improving learning (in total, $85 \%$ of positive answers), the results of the last four questions show how important it is for students to be fully involved in the learning process, in terms of content choice (in total, $92 \%$ of positive answers) and assessment criteria (in total, $87 \%$ of positive answers). (Figure 5)

Q14. The possibility of being able to choose in groups the topic to be studied has increased my motivation to learn.

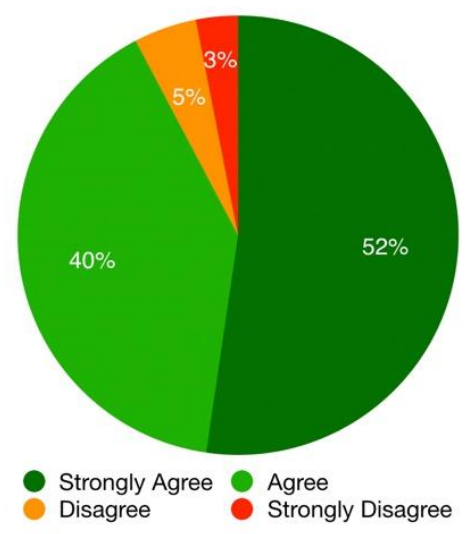

Q15. The possibility of participating in the definition of evaluation criteria has increased my interest in the course.

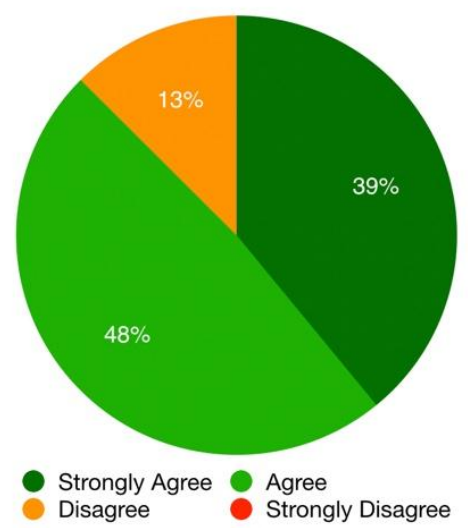

Figure 5. Answers on the role of negotiation, both for the choice of topic (Q14) and the setting of evaluation criteria (Q15)

The role that participation in the setting of evaluation criteria can play in improving the study method has perhaps been less understood, but it has nevertheless achieved an excellent result (in total, $79 \%$ of positive responses). 


\section{Conclusion and Discussion}

This teaching practice is a circumscribed example, both for the number of people involved and for the particular context (the Italian university system), but it shows how it is possible to stimulate motivation and interest by merely using tools and knowledge that we already have at our disposal. The partly free choice of the learning path, for example, is more or less what Kilpatrick (1936), Freinet (1994) and the experiences of Dalton Plan (Parkhurst, 1927) and Winnetka Plan (Washbourne \& Marland, 1963) already stated in the last century. Even the mutual assessment among the groups comes from peer assessment practices (Armstrong, 2011), but in a culture where evaluation plays a fundamental and controversial role in every context (Del Rey, 2013) there is a need to accustom young people to this challenging action. The meaning of a grade usually is opaque, rarely explained to students, especially at university, and it is difficult for them to understand what the main issues of their learning are; they often have no motivated comment of a mark. The co-construction of evaluation criteria can help students to develop a metacognitive reasoning on the sense of evaluation and on what is essential for their learning: knowing from the beginning about what they will be evaluated is an indication of method, because they can better understand how to set up their study, towards what goals move (Sadler \& Good, 2006). Furthermore, the peer assessment experience offers another point of view on objectivity, because it is not the result of a standard structured test but of many different subjectivities.

It is not a question of innovating, but of acting differently, and - as far as possible - acting together with the students, involving them immediately and on many dimensions of the course. Nowadays, more than ever, this involvement is aimed at people who continuously participate, interact, and evaluate: digital media allow it and, in some way, impose it. As mentioned, their cultural habits depend on the media used in their everyday lives. They interact daily with video games and audio-visual products (the new distribution platforms such as Netflix or Amazon Prime Video); provide unceasing evaluations with Likes, Shares, five-star rating systems (Amazon, eBay, TripAdvisor, etc.); communicate knowing they can get immediate feedback (WhatsApp grey and blue checkmarks, or similar). It is difficult to impose anything on these students. From an educational perspective, it is hard to stimulate their motivation. Working on negotiation is also a way for students to understand that participation requires basic knowledge and competences: it is not true that we can say or do what we want just because the medium allows it; our actions and words depend on how and how much they add value to the whole (learning) community and on achieving learning outcomes. It is a matter of media education in a broad sense.

What we argue is that even the current media age seems to be pushing for involvement and participation. If we look at the evolution of teaching methods over the years, we realize that their underlying logic can be polarized between two extremes: transmission and participation. In the first case, the focus is on the relationship between teacher and knowledge; in the second case, the emphasis is on the relationship between student and knowledge (Vial, 1982, Bottero, 2014). We hypothesize that the evolution of this logic (from transmissive to participatory) also depends on the evolution of media and modes of communication.

The method of the lecture, for example, dates back to the Middle Ages, deriving from a phase of interpretation of the text (lectio). It therefore connects to the 'book' medium, based on the mutual comparison between different interpretations of the text: by the teacher and by the students. Instead, the type of lecture we are accustomed to today, the so-called ex cathedra lesson, unidirectional and transmissive, is based on a logic of flow, characteristic of the passage to the electric and audio-visual era (McLuhan, 1962). It is in this period that the method assumes its current peculiarities, and it is in this period that a composite cultural process leads to the elaboration of some communicative theories (the hypodermic needle model or bullet theory) and some psychological and educational theories (behaviourism) based on the transfer of information from an active sender to a passive recipient. Other methodologies, based on a transmissive logic, can be traced back to this age: Skinner's programmed education, for instance, or the first forms of distance education in the 19th century. 
Nevertheless, the logic of flow increasingly lost effectiveness, also because associated with the concept of the uniqueness of the source of information: today, we live in a time of multiple sources. It is always in that period, at the beginning of the 20th century, that the first attempts to overcome this logic arise: from the pedagogical approaches suggested and practiced by pragmatists and active schools (Maria Montessori, Celestin Freinet, Roger Cousinet, John Dewey, William H. Kilpatrick, etc.) to the first practices of cooperative learning (dating back to the 1930s and 1940s, influenced by Dewey and Kurt Lewin) involvement becomes crucial.

From an educational and didactic point of view, the relationship of power between transmission and participation reverses with the transition to the digital age. Some online education settings based on self-learning continue the transmissive logic, but the main methodological approaches have now a constructivist epistemological basis and move towards participation and collaboration: some examples are the several models of Cooperative Learning elaborated in the late 20th century (Barkley, Barkley, Cross, \& Major, 2005), or the Problem Based Learning (Barr \& Tagg, 1995) and the Challenge Based Learning (Johnson, Smith, Smythe, \& Varon, 2009), where the role of inquiry and group activities is central. Somehow, the characteristics of the digital medium seem to endorse these approaches, today more than ever.

The connection between teaching methods and the media deserves a more in-depth study, with a more precise analysis of the historical epochs in which particular methods were born and developed. However, even at this superficial level, it suggests a reflection on the communicative logic that characterizes learning contexts and students. The digital medium today should also be seen from this perspective, not only as a set of products.

\section{References}

Armstrong, J. S. (2011). Natural Learning in Higher Education. Encyclopedia of the Sciences of Learning, Heidelberg: Springer, Retrieved from https://repository.upenn.edu/marketing_papers/140

Barkley, C., Barkley, E. F., Cross, K. P., Major, C. H. (2005). Collaborative learning techniques: A handbook for college faculty. San Francisco, CA, USA: Jossey Bass.

Barr, R. B., Tagg, J. (1995). From Teaching to Learning - A New Paradigm for Undergraduate Education. Change: The Magazine of Higher Learning, 27 (6), 12-26

Barrows, H S. (1996). Problem-based learning in medicine and beyond: A brief overview, New Directions for Teaching and Learning, 68, 3-12.

Bolter J. D., Grusin R. (1999). Remediation. Understanding New Media. Cambridge, MA, USA: The MIT Press.

Bottero, E. (2014). Il metodo di insegnamento. I problemi della didattica nella scuola di base. Milano, Italia: Franco Angeli.

De Kerckhove, D. (1991). Brainframes. Technology, mind and business. Utrecht, Netherlands: BSO/Origin.

Debray R. (2000). Introduction à la médiologie. Paris, France: PUF.

Del Rey, A. (2013). La tyrannie de l'évaluation. Paris, France: La Découverte.

Freinet, C. B. (1994). Euvres pédagogiques. Tome 1 et 2. Paris, France: Seuil.

Freire, P. (1970). Pedagogy of the Oppressed. New York, USA: Continuum.

Fuentealba, C. (2011). The Role of Assessment in the Student Learning Process. Journal of Veterinary Medical Education, 38 (2), 157-162.

Galotti, K. M., Clinchy, B. M., Ainsworth, K., Lavin, B., \& Mansfield, A. F. (1999). A New Way of Assessing Ways of Knowing: The Attitudes Towards Thinking and Learning Survey (ATTLS). Sex Roles, 40 (9/10), 745766

Gee, J. P. (2007). What Video Games Have to Teach Us about Learning and Literacy. New York, USA: Palgrave Macmillan.

Johnson, L. F., Smith, R. S., Smythe, J. T., Varon, R. K. (2009). Challenge-Based Learning: An Approach for Our Time. Austin, Texas, USA: The New Media Consortium. 
Kapp, K. M. (2012). The Gamification of learning and instruction. Game-based methods and strategies for training and education. San Francisco, CA, USA: Pfeiffer.

Kilpatrick, W. H. (1936). Foundations of Method. Informal Talks on Teaching. New York, USA: The Macmillan Company.

McLuhan, M. (1962). The Gutenberg Galaxy: The Making of Typographic Man. Toronto, Canada: University of Toronto Press.

McLuhan, M. (1964). Understanding Media: The Extensions of Man. New York, USA: McGraw Hill).

Mithen, S. (1996). The Prehistory of the Mind. The Cognitive Origins of Art, Religion and Science. London, UK: Phoenix.

Mithen, S. (2001). The Evolution of Imagination: An Archaeological Perspective. SubStance, 94/95, 28-54.

Ong, W. J. (1982). Orality and Literacy. The Technologizing of the Word. New York, USA: Routledge.

Parkhurst, H. (1927). Education on the Dalton Plan. London, UK: G. Bell and Sons.

Roediger III, H. R., and Marsh, E. J. (2005). The Positive and Negative Consequences of Multiple-Choice Testing. Journal of Experimental Psychology: Human Learning \& Memory, 5, 1155-1159.

Sadler, P. M., \& Good, E. (2006). The Impact of Self- and Peer-Grading on Student Learning. Educational Assessment, 11 (1), 1-31

Skidmore, D., \& Murakami, K. (Ed.) (2016). Dialogic Pedagogy: The Importance of Dialogue in Teaching and Learning. Bristol, UK: Multilingual Matters.

Soderstrom, N. C., \& Bjork, R. A. (2015). Learning Versus Performance: An Integrative Review. Perspectives on Psychological Science, 10, 176-199.

Stiggins, R. J., Arter, J. A., Chappuis, J., Chappuis, S. (2007). Classroom Assessment for Student Learning. Doing it right - Using it well. Upper Saddle River, NJ, USA: Pearson.

Vial, J. (1982). Histoire et actualité des méthodes pédagogiques (Paris, France: ESF).

Washburne, C., Marland Jr., S. P. (1963). Winnetka: the history and significance of an educational experiment. Englewood Cliffs, NJ, USA: Prentice-Hall.

Young, M. F., \& Slota, S. T. (2017). Exploding the Castle: Rethinking How Video Games \& Game Mechanics Can Shape the Future of Education. Charlotte, NC, USA: Information Age Publishing. 